\title{
Interview with M Frederick Hawthorne
}

M Frederick Hawthorne is a world-renowned scientist in the field of molecular medicine and a pioneer in boron chemistry. He currently serves as the founding Director of the University of Missouri International Institute of Nano and Molecular Medicine (MO, USA). Prof. Hawthorne is a University of Missouri Curators' Distinguished Professor and University Professor of Chemistry Emeritus of the University of California, Los Angeles (CA, USA). $\mathrm{He}$ is a member of the US National Academy of Sciences and the recipient of many national and international honors, including the 2003 King Faisal Prize in Science, the American Chemical Society's 2009 Priestley Medal and the 201 I National Medal of Science. Prof. Hawthorne has authored or co-authored more than 540 research articles, 30 patents, ten book chapters and two books. Prof. Hawthorne spoke to Future Medicinal Chemistry on how he became involved in the field, the future of boron neutron capture therapy, and provides his advice for the next generation of boron scientists.

Interview conducted by Isaac Bruce, Managing Commissioning Editor.

\section{Q How did you begin your career?}

I was trained as a physical organic chemist and I got my PhD with Don Cram at the University of California, Los Angeles (UCLA; CA, USA). Prof. Cram later won the Nobel Prize and was a very good man to work for. I joined his laboratory in 1949 and was his fifth graduate student. He charmed me with organic chemistry and the things one might do with it and the dependency of properties on structure. He was also enthused about synthesis and mechanisms in the physical organic area. When I left there, I was oriented towards physical organic chemistry and I went to work with George Hammond, who was at that time at Iowa State College (IA, USA), for approximately a year and a half. There, I worked on a project that was unusual in that it was financed by the US Army in the area of nitroform chemistry. It was the chemistry of the anion of that material, and the stuff was tricky to work with as it could explode. The chemistry itself was classified by the Army, which was unusual for an academic post-doctoral researcher, and I was able to do things on the side as well. I published a number of papers with Hammond on other topics.

Q You then went to industry, what sort of work were you researching while there?

My wife and I were expecting a baby in October 1954, so in that summer I started looking for a job. I wanted an academic job but they were impossible to find at that time. I was fortunate again in that George Hammond was a consultant for Rohm and Haas, a firm that had come from Germany to the USA between the World Wars and had built up the acrylate business. The company had its main laboratory in Philadelphia (PA, USA) but it was not well known at that time that Rohm and Haas was a contractor for a research laboratory in Huntsville (AL, USA), which was soon to become a major center for research with rockets and space exploration. The US Army paid for that laboratory. It had 30 chemists, half $\mathrm{PhDs}$ and half technicians. It was very small and in an out-of-the-way place. In order to get people to move there they had to make some special accommodations and among these was the reward of a certain fraction of your time to work on any project that you wanted. Although we were working mainly on solid propellants, we were free to investigate broadly in that area. The company wished to pattern the management and the program after the DuPont central research facility, which was famous for freedom to research and publish. Of course, things had to be cleared by the Army, but basic research was readily approved. Over a 15 -year period the researchers in that little laboratory discovered polyhedral boranes, which we will discuss later, and nitrogen fluorine (NF) derivatives, which were hallmarks in chemistry. The NF field was limited to one or two compounds in 1954 and we found a new method of making $\mathrm{NF}_{3}$ and $\mathrm{HNF}_{2}$, which would react with olefins, and this opened up a whole new area of chemistry.

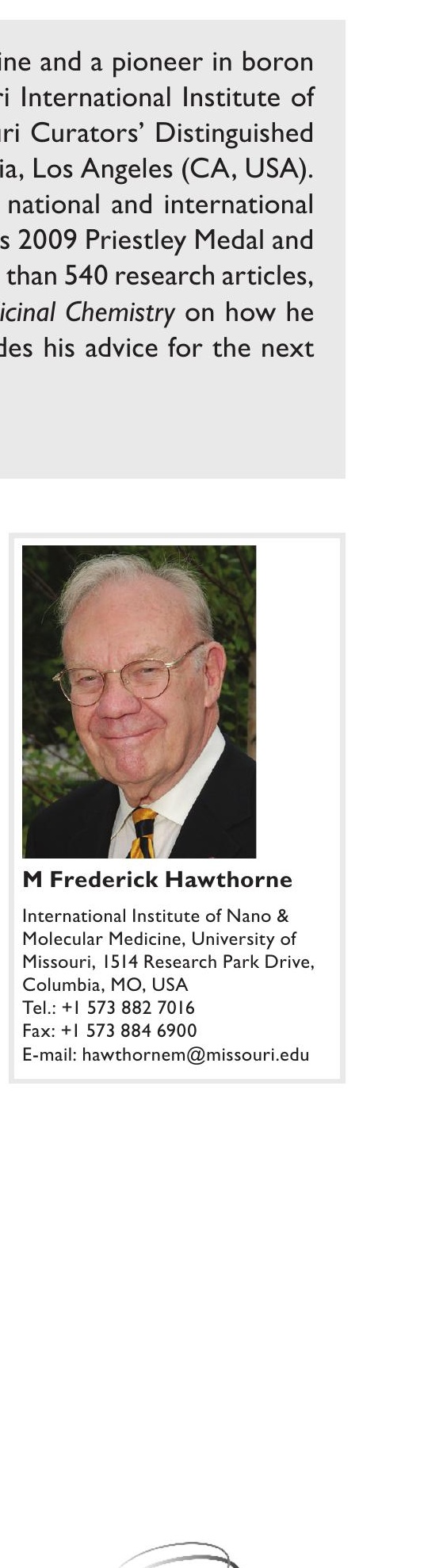

M Frederick Hawthorne

International Institute of Nano \& Molecular Medicine, University of Missouri, 1514 Research Park Drive, Columbia, MO, USA

Tel.: + I 5738827016

Fax: + I 5738846900

E-mail: hawthornem@missouri.edu 


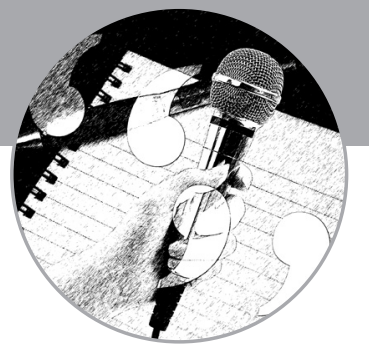

Q How did your research allow you to enter into boron chemistry?

I was initially a laboratory consultant in physical organic chemistry. As a freelance investigator I could go from group to group to see what everyone was working on. They allowed me to work on my own projects, which was encouraging, as I had a strong reputation. I worked on organic compounds that were related to rocketry, such as nitroalkanes and nitrate esters. I wanted to work on something that was fundamental and new. There are a number of reactions with primary nitroalkanes used in a variety of reactions that were textbook classics but no one knew their mechanisms. I set out to reveal some of these, and I did.

We had a change in laboratory management in 1956 with the arrival of Warren Neiderhauser. He was full of ideas and ambitious and wanted our laboratory to excel. He later became a Director of Rohm and Haas, and President of the American Chemical Society; very well respected in his field. He was dissatisfied with our research program, which he thought was outdated. He proposed the NF chemistry program and suggested to the organic group leader that he should find a new synthesis of reactive NF intermediates that could be used as reactive intermediates in the development of new compounds for propellant purposes. This would have been tremendous because the expected performance of NF compounds would have been exceptionally high. In the propellant world, there was a new class of propellant being pursued and manufactured in multi-ton quantities. This was decaborane, $\mathrm{B}_{10} \mathrm{H}_{14}$, which had all kinds of harmful properties. However, if skillfully produced and modified this material could possibly result in a good solid rocket. This became of interest to those in the field. Similar compounds were also being sought as liquid derivatives (by putting alkyl groups on them) for use in jet engines. This was actually accomplished and it cost millions of dollars. Decaborane was available but no one working in that area knew very much about boron chemistry, the reason being that there was very little research being done. Niederhauser knew that I would be interested in this challenge so one day he called me into his office and said that he wanted me to create and lead a new group in our laboratory to perform basic research in boron chemistry. At the time I knew very little about boron chemistry. I thought it was bad stuff but I said yes, I would be happy to do it. I ran to the library and looked up boron chemistry in an old textbook. I figured that this was a real opportunity as no one knew much about it.

Q What were your new group's initial findings?

Being funded by the Army meant that I could not readily access borane starting materials, as they were being made by the Air Force and the Navy, so I had to make my own. I got a cylinder of diborane and I pyrolyzed it in the laboratory. Every day I could make approximately $1 \mathrm{~g}$ of decaborane. I kept making my $1 \mathrm{~g}$ per day and from this we were going to start our research into its properties. I started looking for compounds containing the $\mathrm{BH}$ bond that could be easily made and in which I could regulate the electronic properties of the boron by changing the substituents on the boron. The molecules I came up with were the tertiary amine boranes. I was the first to come up with the synthesis of a wide range of amine boranes, such as the aryls, alkyls and others. I wanted to explore the chemistry of the $\mathrm{BH}$ bond as we changed it by altering the organic substituent and the steric environment. There was the $\mathrm{LiAlH}_{4}$ reduction of boronic acid esters, for example, diethylphenyl boronate, and these conditions along with the respective trialkylamine or pyridine gave the corresponding amine borane. I published approximately 20 papers in this area and established our group as a borane group.

Our group was finally recognized by the Navy and Air Force. We did some exploratory reactions on decaborane as a protonic acid, and I developed a set of reactions that would go beyond $\mathrm{B}_{10} \mathrm{H}_{14}$. A report appeared in the classified literature describing a mysterious new organoborane derivative, which had $\mathrm{BH}$ infrared bands in a different place from its $\mathrm{B}_{10} \mathrm{H}_{14}$ starting material, and had a very high boron content. The reporting laboratory had tried to deduce the composition and the chemistry in order to produce other derivatives, but they could never prove how many hydrogens were in it. I proved it was a $\mathrm{C}_{2} \mathrm{~B}_{10} \mathrm{H}_{12}$ icosahedral structure (later called carborane) isoelectronic with $\left[\mathrm{B}_{12} \mathrm{H}_{12}\right]^{2-}$. My report was the first analysis of an icosahedral carborane. This was initially classified but its structure was soon disclosed and it became declassified. Many of the things I found at this time were published, for two reasons: first, I was in a good place to publish, and second, and most importantly, I was one of the few people in the world who understood the pertinent reactions.

In the area of mechanisms, I was very close to Bill Lipscomb at Harvard University (MA, USA), who had worked out the topology of bonding for the boranes, which was extended for carboranes. I 
wanted to base the bonding descriptions on electronic rules. Our laboratory developed a reputation of being a leader in that area.

During that period we started new work for the Army and the Air Force, who were very interested in carboranes. I made a batch of diacetylene and I ran the carborane reaction with that and got carboronyl acetylene and bis-carborane, which was a higher melting compound than carborane and less volatile but had a lot of boron in it. When I went to Wright Air Force Base (OH, USA) to give my quarterly review I had just isolated this and had about $1 \mathrm{~g}$ in a little vial in my pocket, and I showed it to Air Force management. I wrote the structure for them and they said, "You really have that?" I said yes and they asked how much decaborane I had, which was the key starting material for all carboranes. The program manager immediately arranged the shipment of 1 ton of decaborane to my laboratory. We put it in the hallway, in the laboratory, everywhere! We had enough to run our manufacturing program so we could scale up.

\section{Q How did you enter back in to academia?}

In 1960 I was invited to Harvard to be a visiting lecturer, so I thought it would be a good chance to enter into academia and Lipscomb promoted it. My boss at Rohm and Haas granted me a leave of absence and I moved to Cambridge (MA, USA). Following that, I temporarily went back to Rohm and Haas as a laboratory head and my laboratory moved to the industrial part of Philadelphia. I used to go to work in the dark and come home in the dark. I worked on acrylate esters and I did not enjoy it.

My undergraduate alma mater, Pomona College, was very close to Riverside (CA, USA), which had a new chemistry program funded by the University of California. Rohm and Haas in Philadelphia was doing their best to accommodate me and they offered many generous incentives while I was there, but I missed my boron chemistry and I had to get back to it. My former professor and life-long friend, R Nelson Smith, was in very close contact with the people in the 'new campus' chemistry department and he put a good word in for me. I got a full professorship teaching organic chemistry to undergraduates and I could pursue my research in boron chemistry free from government complications. I was successful.

In 1968, UCLA offered me a full professorship and I moved back there. I stayed there many, many years and I became an emeritus University Professor in 2006. At that same instant I became a professor at the University of Missouri (MO, USA), which came with the directorship of the new International Institute of Nano and Molecular Medicine.

Q You have worked with many of the top researchers in the field from the very beginning of your career, how did you initially become in contact with Herbert Brown?

I heard from Herbert Brown after I published a note in The Journal of Organic Chemistry on the hydroboration of 1-octene with pyridine borane. He was incensed that I had entered the hydroboration field with a different type of hydroboration reaction and he told me I should get out of the field as it was his. I took it very seriously as I was a very sensitive young guy. Eventually, Herb Brown and I became very good friends and he helped me in many ways. I have always appreciated that initial contact with him because he was, above all things, an honest man.

Q How has boron chemistry as applied to boron neutron capture therapy developed in recent years?

Early in my career at Rohm and Haas, when I first had boranes available, I actually discovered that polyhedral boranes, such as $\left[\mathrm{B}_{12} \mathrm{H}_{12}\right]^{2-}$ and $\left[\mathrm{B}_{10} \mathrm{H}_{10}\right]^{2-}$, should be isoelectronic with their corresponding carboranes, but these carboranes were not known at that point. It became clear to me, having these very stable polyhedral borane species, that we should derivatize them with organic groups and incorporate them into organic molecules, and that we ought to be able to use them in all sorts of medically and pharmaceutically important devices and agents. So, I have always had an interest in the pharmacology of these molecules.

Boron neutron capture therapy (BNCT) caught my attention early on. It seemed to me that the molecules we were dealing with, which were hydrolytically stable, could be derivatized with organic compounds and used for BNCT. Even at Rohm and Haas in $1956 \mathrm{I}$ had this in mind and made the very first polyhedral anion, $\left[\mathrm{B}_{10} \mathrm{H}_{10}\right]^{2-}$, which was very stable, and I gave that to the BNCT researchers at Ohio State University, based in Columbus (OH, USA), and other institutions. I met 


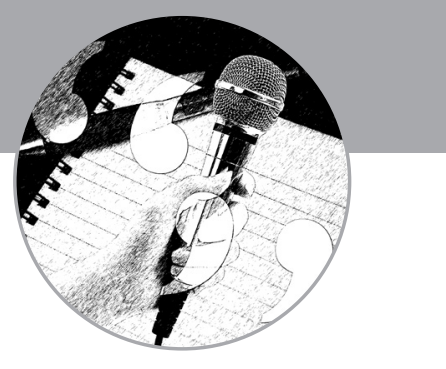

an MD, Dr William Sweet, who was leading the BNCT human clinical trial around that time, and I sent him $\mathrm{Na}_{2}\left[\mathrm{~B}_{10} \mathrm{H}_{10}\right]$ to see if it was toxic. It was not. Sweet's group administered this salt to selected patients in the study; it was recovered in their urine and identified by NMR. That made me think there were more opportunities out there.

In general, boron chemistry has not developed with time and this area is essentially dormant except for the new chemistry that we have discovered and are in the process of developing. This work is described below.

\section{Q Do you have any recent findings in your BNCT research program?}

I have always had a BNCT program, whether active or dormant, and we still do. One reason I am in Missouri is that the University of Missouri built a neutron beam for me, which we can use for exploratory studies with mice and other small animals. At UCLA before I moved, we had found that liposomes were very good carriers for target compounds for BNCT. They had excellent properties in terms of uptake for regulating tumors and safety in use. We have recently carried out studies, in addition to biodistribution investigations, into actual radiation experiments and these have been totally successful. We have not lost a single mouse because of the toxicity of the target compounds. The target compounds we have synthesized for use are very high in boron content and they leave the body at a rate that is quite convenient for BNCT. We can inject a mouse and $30 \mathrm{~h}$ later the concentration of boron in tumors is at its maximum and, then, by the time it decays, approximately a day and a half later, there is virtually no boron remaining. We have a class of compounds that we have created from first principles and, in fact, two of them sharing a liposome are doing well in our mouse studies. In addition to our mouse studies we have sent the compounds to a BNCT laboratory in Argentina that uses hamsters, which are larger and more human-like. Their evaluation has been completely congruent with our mouse results.

We hope to install a beam at University of Missouri for larger animals so that we can study the new compounds in dogs, or an animal of that size, which you must do before moving to people, and that same neutron beam could be used for human studies. We are seriously moving forward towards actual clinical applications.

In the meantime we have discovered another new type of borane delivery system, which is even richer in boron content than the compounds described above. The new compounds are approximately $50 \%$ boron by weight and the previous compounds were approximately $30 \%$. We now have the positive results to encourage further work.

Q How has the funding situation differed over your time in research?

In general, people do not have the patience they used to have in learning new things; they want everything to be given to them in a computer and all set up, ready for someone to press a button. That is not how it works. Those who want to stay at that level of involvement are always going to be on the outside when success is possible. There is more and more of this attitude in younger researchers, so we need to maintain standards while pushing the science. This is true throughout boron chemistry when applied to biology. Funding is presently slow and new research programs seem to be more difficult to initiate than they once were. Patience is a virtue at this point in time.

Q You have had over $200 \mathrm{PhD}$ and post-doctoral students in your laboratory, how has the research and the manner in which students conduct their research differed over the years? Fewer strong researchers are available now. People are not going into chemistry like they used to. I see a lack of discipline and it is holding us back. Many young researchers have great ideas but they do not want to be involved for a very long time in graduate school and postdoctoral work. Success in this area lies more and more in the hands of the individual who is willing to sacrifice early personal gain and recognition in order to perfect their craft. I would encourage young people to hang in there and accept that it takes years to establish the level of expertise needed in this field. To succeed, one must enjoy chemical research.

There is an area out there that I really think we should go for: boron chemistry for medical devices. The chemistry of carboranes and polyhedral boranes is vast. Compared with carbon it is not of the same order of magnitude. Boron is very adaptable at making certain molecular functions work, creating new compounds, manipulating biology. The easiest way of bringing inorganic chemistry to biology is the synthesis of carboranes and polyhedral boranes, whose function depends not on 
the carbon but the boron, such as redox chemistry. There are a lot of metallacarboranes and metallaboranes that could be synthesized in order to bring electron-transfer reactions to biomolecules, and one could use this to set up chains of redox processes that could lead to one or more pharmaceuticals and biologically active materials. Things are not thought of in that way and that is unfortunate. There are things out there that once you have a handle on them many other things will be revealed and they will be quite different from what we think of today in terms of pharmaceuticals.

Q Do you think in the next 5-10 years this will come to fruition?

Unless we have an international collapse in terms of financial support for our science, yes. Left to our own devices and given the freedom and support we expect, then I think 5-10 years is a fair length of time. The trouble is that fewer people want to work that hard in science and particularly less known boron science. People have become followers of professors that they are in contact with and they think how their professors think, and act as they act: there are very few that are cast out on their own who have the ability to survive and do something truly original. Somewhere in the world there are people like this. Every country has someone who has these ideas, but trying to collect these ideas, finding out if they could work and globally communicating with each other are difficult matters.

What words of advice would you give to young scientists envisioning a career in the field? First, we should give an indoctrination lecture to show them where boron chemistry stands in relation to other subsets of chemistry. Show them that boron chemistry has just been touched; we have not had the time or the people or resources to push this to the limit, which is not yet in sight. What it will take is some kind of breakthrough, perhaps even something such as BNCT, which has been around for years but if we could make BNCT really work, and show them that it is only possible due to the properties of boron.

The pharmaceutical business, the people who have the means to bring these things forward quickly and identify the correct avenues in industry, are not trained in boron chemistry: they are most commonly organic chemists. You have seen the popularity of the trifluoromethyl group suddenly appear and now there are a large number of bioactive molecules with fluorine in them: but that is inorganic! You hardly see anything with boron in it, yet it has such unique structures. Some of us published work that has demonstrated that boron could be a surrogate for carbon groups and, even further, give superior performance. Things such as this are not commonly thought of. There is a lack of connection between the people who are controlling the research and what may be going on in academia and other places.

The days of pure curiosity, research for fun, which is how I still look at research, are nearly gone. There are people out there for which research has always been a dollar and cent thing. My kind of chemists are out there. It might be worth it to create a new professional organization, which would fold together a pharmaceutical borane chemistry and carborane chemistry, not calling it boron chemistry but giving it a different name. I would like to see interest stimulated in that direction.

We do not know the limits of boron chemistry but they seem vast. If we look at all the organic chemistry we have sorted through and the few good drugs we have, you have to say that it would be a good idea to do this again but do it with boron in a slightly different way. One way through this maze is to take advantage of boron nuclear properties, which gives you a foothold in its uses in imaging or therapy. We need more freedom.

Looking back through your career, which discovery/piece of work are you most proud of? I think probably the thing that stands out is the prediction, synthesis and characterization of the first metallacarboranes, where transition metals were introduced into boron cages. That work was initiated at Riverside. I have done many other things but that was very pleasing because it was modelled after ferrocene in terms of bonding. The chemistry was different from what we knew and it worked. That was the signal that demonstrated to me that boron chemistry could be understood and the knowledge people had of organometallic chemistry could be extended. This is the kind of thing you need to know about if you are to discover and make new medicines.

Many of the discoveries that we have made were serendipitous, but what made it possible for untried reactions to lead to new fields and significant new discoveries, was very careful experimental work. I take pride in that. A reacts with B and you have a good idea that it is going to do something 


\section{NEWS \& ANALYSIS | INTERVIEW}

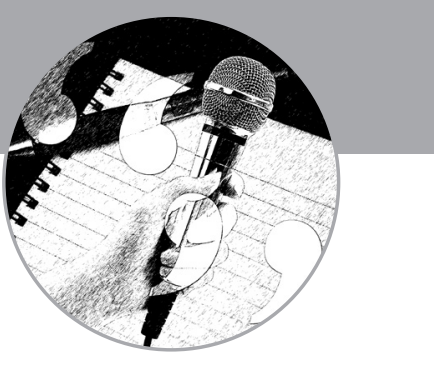

interesting rather than something predicted. If you can live with that philosophy and do careful work, you can find the things that are unexpected, then interpret them and see how they fit in. Mostly, we create things that are not predicted; things we can imagine, but not the first things that we expect. Serendipity has played a large part but it is only because of the skill with which people carried out the research, identified the products, characterized them, worried about the structures and worked out the reaction mechanisms. These are the things that have fuelled the field.

\section{Disclaimer}

The opinions expressed in this interview are those of the interviewee and do not necessarily reflect the views of Future Science Ltd.

\section{Financial \& competing interests disclosure}

The interviewee has no relevant affiliations or financial involvement with any organization or entity with a financial interest in or financial conflict with the subject matter or materials discussed in the manuscript. This includes employment, consultancies, honoraria, stock ownership or options, expert testimony, grants or patents received or pending, or royalties.

No writing assistance was utilized in the production of this manuscript. 